\title{
Das Beschneidungs-Urteil aus Köln und die Frage Wozu?
}

VB verfassungsblog.de/das-beschneidungsurteil-aus-kln-und-die-frage-wozu/

Maximilian Steinbeis Mi 27 Jun 2012

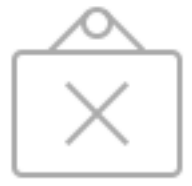

Eigentlich staunt man fast, dass in der ganzen aufgeheizten und -gehetzten Atmosphäre um den Islam das Thema Beschneidung erst jetzt so richtig knallt. Wir hatten Schleier und Burka, wir hatten Schächtung, wir hatten das Bilderverbot. Aber die Vorhaut in den Mittelpunkt des christlich-abendländischen Kulturkampfes zu stellen, hat sich bisher noch niemand so recht getraut.

Ausgerechnet in Köln, der Stadt der rotnasigen Leeve-un-leeve-losse-Mentalität, ist es jetzt passiert, schon wieder dort, müsste man nach Moscheenstreit und "Pro Köln" eigentlich sagen: Das Landgericht Köln findet, kleinen Jungen aus muslimischen oder jüdischen Familien ihre Vorhaut wegzuoperieren, sei Körperverletzung und strafbar.

Was juristisch von diesem Urteil zu halten ist, wird Georg Neureither für den Verfassungsblog analysieren, der versteht mehr von Religionsverfassungsrecht als ich.

Mir geht es hier um Rechtspolitik: Ich halte dieses Urteil für eine schier unglaubliche Gemeinheit, wenngleich eine ziemlich raffiniert gemachte.

\section{Wozu?}

Wenn dieses Urteil richtig wäre, dann müssten ausgerechnet deutsche Staatsanwälte - als einzige auf der ganzen Welt, wenn ich nicht irre - Juden verfolgen, weil sie tun, was Juden tun. Das ist für sich genommen schon mal ziemlich unglaublich.

Die Frage, die ich mir stelle, ist aber vor allem: Wozu? Wo ist der Missstand, dem mit Hilfe des Strafrechts abgeholfen werden muss? Wo sind die Opfer, die der Staat mit Hilfe des Strafrechts vor Misshandlung schützt? Wieviel unter den Milliarden beschnittenen muslimischen und jüdischen (und christlichen) Männern vermissen ihre Vorhaut als einen integralen Teil ihres Körpers? Wozu also muss diese Tat unbedingt kriminalisiert werden? 
tatbestandsmäßig Körperverletzung ist, wenn ein Arzt eine Spritze setzt, dann ist es doch wohl dreimal Körperverletzung, wenn er eine Vorhaut abschneidet. Und Körperverletzung war schon immer strafbar.

Wogegen auf begriffsjuriprudenzieller Ebene wenig zu sagen ist. Aber da wird doch bitte niemand drauf reinfallen. Natürlich kriminalisiert das Kölner Urteil ein Verhalten, das bislang sozial vollkommen akzeptiert war. Ich frage mich: Wozu? Was bezwecken sie damit?

Das ist nur zum Schutz des Kindes, wird vermutlich die Kölner Strafjustiz erwidern. Zum Schutz seiner körperlichen Integrität vor nicht medizinisch indizierten Eingriffen.

Wogegen wiederum auf begriffsjurisprudenzieller Ebene wenig zu sagen ist. Aber das beantwortet nicht die Frage, warum dieser ganz spezielle Eingriff einer ist, für den unbedingt jemand bestraft werden muss. Wenn ich meiner kleinen Tochter die Ohrläppchen stechen lasse, schreit doch auch keiner nach dem Staatsanwalt. Also: Wozu?

Meiner Meinung nach liegt die Antwort auf der Hand: Hier geht es darum, zu verhindern, dass Leute als Muslime oder Juden geboren werden. Hier geht es darum, Religionen, oder jedenfalls: diese beiden Religionen zu Vereinen downzugraden, denen man, sobald man die dazu nötige Mündigkeit besitzt, beitreten kann, wenn man unbedingt will.

Mit anderen Worten: Das LG Köln macht das Strafrecht zu einem Mittel eines antireligiösen Kulturkampfs. Wer das für liberal und aufgeklärt hält, sollte noch mal nachdenken.

\section{Wie kriegt man das wieder aus der Welt?}

Raffiniert an dem Urteil ist, dass der Angeklagte freigesprochen wurde: wegen "unvermeidbarem Verbotsirrtums", d.h. man konnte von dem Arzt nicht erwarten, das Kriminelle seines Handelns zu erkennen.

Das klingt entlarvend, fast entwaffnend, ist aber in Wahrheit ein höchst geschickter Schachzug: Denn damit kann der Arzt kein Rechtsmittel einlegen. Das Urteil wird rechtskräftig und steht künftig allen, die das gut finden, als Referenz zur Verfügung. Es gibt insbesondere keine Verfassungsbeschwerde nach Karlsruhe, wo - da würde ich meine Vorhaut darauf verwetten - das Urteil mit Donnerhall aufgehoben werden würde. All das wird es mangels Beschwer des Angeklagten nicht geben. Raffiniert gemacht, wie gesagt.

Andererseits kann diese Entscheidung nicht einfach so stehen bleiben. Der Islam gehört schließlich zu Deutschland, wie wir von unserem vormaligen Bundespräsidenten wissen. Und wer diese Ansicht nicht teilt, wird doch jedenfalls hoffentlich nicht widersprechen, wenn ich das Judentum als Teil Deutschlands bezeichne. Und Juden und Muslime müssen in Deutschland die für ihre Religionszugehörigkeit konstitutiven und für niemanden schädlichen Riten vollziehen können, ohne mit dem Strafrecht in Konflikt zu geraten.

Notfalls muss der Gesetzgeber das Problem lösen. Dass man da leicht in die fürchterlichsten Abgrenzungsprobleme gerät, ist mir klar. Wir wollen nicht, dass künftig irgendeine Sekte ihre Babys tätowiert.

Aber das Problem hätte man dadurch vermieden, dass man einfach gesetzlich klarstellt, dass eben die jüdische und muslimische Beschneidung nicht unter $\S 223$ StGB fällt. Die damit implizierte Bevorzugung dieser beiden Religionen ließe sich dadurch rechtfertigen, dass die Unschädlichkeit ihrer Riten nach jahrtausendelanger Praxis keinem rechten Zweifel mehr unterliegt. Das müsste doch funktionieren, oder nicht?

LICENSED UNDER CC BY NC ND

SUGGESTED CITATION Steinbeis, Maximilian: Das Beschneidungs-Urteil aus Köln und die Frage Wozu?, VerfBlog, 2012/6/27, http://verfassungsblog.de/das-beschneidungsurteil-aus-kln-und-die-frage-wozu/. 